\title{
Use of lidocaine patches for neuropathic pain in a comprehensive cancer centre
}

\author{
Julia Ann Fleming MBBS PhD FANZCA FFPMANZCA Dip Med (Pain Management), \\ Bradley David O'Connor MB ChB FANZCA ${ }^{2}$
}

\begin{abstract}
JA Fleming, BD O'Connor. Use of lidocaine patches for neuropathic pain in a comprehensive cancer centre. Pain Res Manage $2009 ; 14(5): 381-388$.
\end{abstract}

BACKGROUND: There are few reports of the use of the lidocaine $5 \%$ patch $(\mathrm{L} 5 \% \mathrm{P})$ for neuropathic pain (NP) in the cancer patient. Within a comprehensive cancer centre, L5\%P has been prescribed by the Pain and Palliative Care Service (Peter McCallum Cancer Centre, East Melbourne, Victoria, Australia) for selected patients with NP since 2001.

OBJECTIVE: To retrospectively audit the use of $\mathrm{L} 5 \% \mathrm{P}$ within a comprehensive cancer centre.

METHODS: All L5\%P prescriptions up to January 2009 were listed and patient medical records were searched to determine neuropathic pain syndromes treated, the presence of allodynia, previous analgesic medications, treatment duration and outcome.

RESULTS: L5\%P was prescribed for 97 patients, most frequently for persistent postsurgical NP $(n=26)$, postherpetic neuralgia $(n=24)$ and cancer-related NP $(n=18)$. Six patients had no history of cancer and two patients never applied L5\%P. Reviewers classed L5\%P analgesic efficacy as 'potent' in $38 \%$ of patients with postherpetic neuralgia, $35 \%$ of patients with postsurgical pain, $27 \%$ of patients with NP after other treatments for cancer and $12 \%$ of patients with NP attributed to cancer alone. Allodynia featured in at least $60 \%$ of patients. Where allodynia was present, the efficacy of L5\% $\mathrm{P}$ was assessed as 'potent' in $38 \%$ and 'partial' in $24 \%$, but 'ineffective' in 26\%, and 'causing worse pain' in $3.4 \%$ of patients. Treatment duration extended longer than one month in 52 patients, longer than two months in 29 patients and longer than one year in 13 patients. Therapy was ceased due to skin irritation in seven patients. The outcomes in relation to other reports are discussed.

CONCLUSION: The present data support trials of L5\%P for cancer patients with NP syndromes associated with allodynia.

Key Words: Audit; Lidocaine 5\% patch; Neuropathic cancer pain

\section{Utilisation des timbres de lidocaïne pour la douleur neuropathique dans un centre d'oncologie}

HISTORIQUE : On dispose de rapports peu nombreux sur l'utilisation des timbres de lidocaïne à $5 \%$ (TL à $5 \%$ ) dans la douleur neuropathique (DN) chez des patients cancéreux. Le service du traitement de la douleur et des soins palliatifs d'un centre d'oncologie (le Peter McCallum Cancer Centre, East-Melbourne, Victoria, Australie) prescrit des TL à $5 \%$ à des patients sélectionnés souffrant de DN depuis 2001.

OBJECTIF : Évaluer de manière rétrospective l'utilisation des TL à $5 \%$ dans un centre d'oncologie.

MÉTHODE : On a relevé toutes les ordonnances de TL à $5 \%$ jusqu'à janvier 2009 et passé en revue les dossiers médicaux des patients afin de recenser les syndromes de douleur neuropathique traités, la présence d'allodynie, les traitements analgésiques antérieurs, la durée des traitements et leurs résultats.

RÉSULTATS : Les TL 5 à \% ont été prescrits à 97 patients, le plus souvent pour une DN post-opératoire persistante $(n=26)$, une névralgie postzostérienne $(n=24)$ et une DN liée au cancer $(n=18)$. Six patients ne présentaient aucun antécédent de cancer et deux n'ont jamais appliqué leurs TL à $5 \%$. Les examinateurs ont qualifié l'efficacité analgésique des TL à $5 \%$ de «puissante » chez $38 \%$ des patients souffrant de névralgie post-zostérienne, chez $35 \%$ des patients souffrant de douleur postopératoire, chez $27 \%$ des patients souffrant de DN consécutive à d'autres traitements pour le cancer et chez $12 \%$ des patients souffrant de DN attribuable au cancer seulement. L'allodynie était présente chez au moins $60 \%$ des patients. En présence d'allodynie, l'efficacité des TL à $5 \%$ a été qualifiée de "puissante » chez $38 \%$ des patients et de "partielle » chez $24 \%$, mais « négligeable » chez $26 \%$ et « responsable d'une aggravation de la douleur » chez 3,4\%. La durée du traitement a été de plus d'un mois chez 52 patients, de plus de deux mois chez 29 patients et de plus d'un an chez 13 patients. Le traitement a été cessé en raison d'une irritation cutanée chez sept patients. Les résultats en relation avec d'autres rapports sont abordés.

CONCLUSION : Les données actuelles justifient la réalisation d'essais sur les TL à $5 \%$ chez des patients cancéreux souffrant de syndromes de DN associés à l'allodynie.

Teuropathic pain is a common problem encountered in $\mathrm{N}$ patients with a current or past diagnosis of cancer. Neuropathic mechanisms were inferred in $40 \%$ of patients with cancer pain in an international, multicentre, prospective survey (1); subsequent evaluation of a revised Edmonton Staging System suggested a $17 \%$ incidence of neuropathic pain in cancer patients referred to a palliative care service (2). Such pain is often recognized by the presence of distressing, touch-evoked allodynia, burning pain, dysesthesias, hyperalgesia or paroxysmal pain. Patients may have neuropathic pain caused by infiltration, compression or distension of nervous tissue by the cancer itself, often presenting as a mixed neuropathic-nociceptive pain syndrome. Many patients have longstanding neuropathic pain consequent to anticancer therapies, including surgery, radiation therapy and chemotherapy, or a paraneoplastic phenomenon. In addition, other unrelated neuropathic pain states occur coincidental to cancer, possibly raising concerns of tumour progression. Notably, postherpetic neuralgia (PHN) remains an important cause of intractable neuropathic pain in the cancer setting, particularly in older patients and those who are

Work originated from the Peter McCallum Cancer Centre, St Andrews Place, East Melbourne, Victoria, Australia. ${ }^{1}$ Professor Tess Cramond Multidisciplinary Pain Centre, Royal Brisbane and Women's Hospital, Herston, Queensland; 'Department of Anaesthesia, The Northern Hospital, Epping, Victoria, Australia

Correspondence and reprints: Dr Julia Fleming, Professor Tess Cramond Multidisciplinary Pain Centre, Royal Brisbane and Women's Hospital, Herston, Queensland, Australia 4029. Telephone 61-7-3636-7130, fax 61-7-3636-6142, e-mail Julia_Fleming@health.qld.gov.au 
immunosuppressed. Many patients experience intractable neuropathic pain long after cancer is controlled.

Within a comprehensive cancer centre, patients may be referred for management of all modalities of neuropathic pain, regardless of the relationship of pain to cancer and whether cancer is active or in remission. The complex nature of neuropathic pain in the individual with cancer presents considerable therapeutic challenges to treating clinicians, in addition to causing distress, anxiety and frustration in patients, their families and caregivers. Optimal multimodal therapy may be compromised by multiorgan disease, polypharmacy and other comorbidities. Therapeutic approaches to cancer-associated neuropathic pain in current adult cancer pain guidelines $(3,4)$ are largely derived from recommendations for chronic nonmalignant neuropathic pain, based on evidence from large trials in diabetic peripheral neuropathy and PHN, in addition to smaller controlled and uncontrolled studies, case series and expert opinion (5). Whereas the National Comprehensive Cancer Network 2008 Adult Cancer Pain Guideline (4) recommend that topical lidocaine patch formulations be considered for peripheral neuropathic pain after trials of anticonvulsants and antidepressant adjuvant therapy, the Scottish Guideline (3) working group could identify no evidence to support the use of the lidocaine $5 \%$ plaster for cancer pain.

Given the common occurrence of PHN and other neuropathic pain in the cancer patient, together with evidence for the use of the lidocaine $5 \%$ patch (L5\%P) for the pain of PHN and other focal peripheral neuropathies $(6,7)$, in 2001, the Pain and Palliative Care Service at the Peter MacCallum Cancer Centre (East Melbourne, Victoria, Australia) first sought to treat patients with L5\%P using the Lidoderm 5\% (Endo Pharmaceuticals, USA) formulation, which was not registered for use in Australia but was obtainable through a national Special Access Scheme. L5\%P is described as a targeted peripheral analgesic, providing topical delivery of lidocaine to damaged or sensitized peripheral nerves to produce analgesia without other sensory deficit. Patients were advised to apply the requisite number of patches (ranging from onesixth of one patch up to three patches) to the area of neuropathic pain or sensitivity, over unbroken skin for $12 \mathrm{~h}$ daily, to limit systemic lidocaine absorption and local skin reactions, based on the current United States Food and Drug Administration-approved treatment protocol for PHN. Advice was given to cease L5\% $\mathrm{P}$ use if any untoward skin irritation or rash developed. A preliminary audit of patients treated up to January 2004 suggested that L5\%P treatment improved analgesia in most patients with PHN, but the response was variable in other neuropathic pain conditions. Anecdotal opinion considered the topical therapy to be successful when touch-evoked allodynia was a feature of pain. The following is a report of a subsequent, more comprehensive audit of all patients prescribed L5\%P for neuropathic pain from June 2001 to January 2009 , completed to facilitate the development of therapeutic guidelines for lidocaine patch use at the Peter MacCallum Cancer Centre and identify key issues for future controlled studies of L5\%P in patients with cancer.

\section{METHODS}

The retrospective audit covered the full period of availability of Lidoderm 5\% patches, from August 2001 to January 2009.
Approval was obtained from the Peter MacCallum Cancer Centre Expedited Ethics Review Committee to audit the prescribing of Lidoderm 5\% patches. Pharmacy records were sought to identify all prescriptions for L5\%P and produce listings of inpatients and outpatients prescribed L5\%P, in addition to the total number of prescriptions, patches and cost of patches prescribed for each patient. Hospital medical records, both paper-based and electronic, were then searched to obtain patient demographic information and any documentation relating to $\mathrm{L} 5 \% \mathrm{P}$ prescribing for each patient, including the following: the nature of neuropathic pain, presence or absence of allodynia and any stated indication for commencement of L5\%P; analgesic medications trialled, and the seniority of the L5\% prescriber and completion of Special Access Scheme documentation; the duration of therapy; and L5\%P treatment efficacy, reason for L5\%P cessation and the occurrence of any skin rash, erythema or sensitivity.

Pharmacy and medical records were reviewed independently by one of two clinicians - a senior pain service consultant who had originally sought approval to prescribe L5\% within the cancer centre in 2001 (JF), or a registrar undertaking a pain service rotation $\left(\mathrm{BO}^{\prime} \mathrm{C}\right)$. All audit data then underwent final review by the senior investigator and any discrepancies or records of concerns were discussed to reach a consensus opinion. The intent of the audit was to evaluate the perceived benefits of L5\% , and to investigate clinical documentation and prescribing practices relating to $\mathrm{L} 5 \% \mathrm{P}$ within the pain and palliative care services. The investigators assessed L5\%P efficacy based on medical documentation of the preliminary patient assessment and subsequent follow-up visits. L5\%P was then classified as having 'potent analgesic effect', 'partial analgesic effect', 'no analgesic effect' or causing 'worse pain', based on any documented description of analgesic benefit, patient opinion, reduction of other medications and stated improvements in function or quality of life. Where documentation was absent or unclear, L5\%P effect was classified as 'not stated'. No consistent formal assessment tools were used during the full audit period. Any analgesics trialled before L5\%P were grouped by pharmacological category and response categorized as 'no effect', 'inadequate effect', 'incomplete effect', 'not tolerated' or 'not stated'.

The audit was conducted in three phases: August 2001 to January 2004 (JF), January 2004 to August 2006 (BO'C; review JF), and September 2006 to January 2009 (BO'C, JF); a preliminary analysis of data from the first audit period was performed and presented at a regional meeting in 2004 (JF). The data from all audit periods was then pooled for the present analysis. Data for individual patients who overlapped two or more audit periods were combined to avoid any duplication. Patient data were de-identified before subsequent analysis. Patients were grouped according to the primary mechanism of neuropathic pain for which L5\% $\mathrm{P}$ was prescribed, into the following groups: PHN; neuropathic pain directly attributed to cancer infiltration, compression or distension; neuropathic pain related to surgical treatment for cancer; neuropathic pain following other or multiple treatments for cancer, in which the etiology of pain was unclear; and mixed pain syndromes, in which several mechanisms of neuropathic pain appeared to coexist. Overall demographic details of the full dataset were summarized and simple descriptive statistics used to evaluate the data. 
TABLE 1

Demographic data

\begin{tabular}{lc}
\hline Patients prescribed L5\%P, $\mathbf{n}$ & \\
Total & 97 \\
Men & 51 \\
Women & 46 \\
Age, years & \\
Median & 61 \\
Range & $19-99$ \\
Cancer status, $\mathbf{n}$ & \\
Current malignancy or in remission & 91 \\
No cancer diagnosis with PHN or chronic pain & 6 \\
L5\%P prescriber, $\mathbf{n}$ & \\
Pain or palliative care specialist & 71 \\
Registrar, resident or fellow & 26 \\
\hline
\end{tabular}

L5\%P Lidocaine 5\% patch; PHN Postherpetic neuralgia

TABLE 2

Neuropathic pain mechanism and presence of allodynia

\begin{tabular}{lcccc}
\hline & \multicolumn{4}{c}{ Allodynia, $\mathbf{n}$} \\
\cline { 2 - 5 } Neuropathic pain syndrome & Present & Absent & stated & Total \\
\hline PHN & 16 & 1 & 7 & 24 \\
Postsurgical treatment for cancer & 21 & 4 & 1 & 26 \\
Cancer etiology & 6 & 2 & 10 & 18 \\
Other/multiple treatments for cancer & 5 & 2 & 4 & 11 \\
Mixed: Cancer \pm PHN \pm treatment & 8 & 0 & 0 & 8 \\
Other unrelated chronic pain & 2 & 4 & 3 & 9 \\
Pain etiology not indicated & 0 & 0 & 1 & 1 \\
All patients & 58 & 13 & 26 & 97 \\
\hline
\end{tabular}

PHN Postherpetic neuralgia

\section{RESULTS}

During the period August 2001 to January 2009, L5\%P was prescribed for 97 adult patients. Table 1 indicates demographic data, and shows an even sex distribution and wide range of patient ages from 19 to 99 years. The majority of L5\%P prescriptions were initiated by pain or palliative care specialist consultants, with the residual being prescribed by medical staff in training under the guidance of the palliative care team. While most patients had active malignancy or cancer in remission, a small proportion (6\%) were outpatients referred for palliative care for chronic neuropathic pain syndromes associated with other medical conditions.

Most patients for whom L5\%P was prescribed had received many analgesic medications before referral to the pain and palliative care service. Pharmacy and medical records indicated that patients were prescribed a median of four medications for pain (range one to 11 ) before L5\%P prescription, including one or more tricyclic antidepressants (prescribed for $n=34$ patients), gabapentin and/or pregabalin $(n=76)$, other anticonvulsants $(\mathrm{n}=15)$, nonsteroidal anti-inflammatory drugs $(n=30)$, acetaminophen $(n=40)$, weak opioids $(n=36)$, strong opioids $(n=63), N$-methyl-D-aspartate receptor antagonists $(n=19)$, clonidine $(n=9)$, membrane stabilizers $(n=5)$, venlafaxine $(n=4)$, topical therapies $(n=9)$ and corticosteroids for pain $(n=11)$, without adequate analgesia being achieved.

The neuropathic pain groups for which L5\% $\mathrm{P}$ was prescribed, and any documented presence or absence of allodynia,
TABLE 3

Documented lidocaine patch efficacy

\begin{tabular}{|c|c|c|c|c|c|c|}
\hline \multirow[b]{2}{*}{$\begin{array}{l}\text { Neuropathic pain } \\
\text { syndrome }\end{array}$} & \multicolumn{6}{|c|}{ Analgesic effect, $n$} \\
\hline & Potent & Partial & None & $\begin{array}{l}\text { Worse } \\
\text { pain }\end{array}$ & $\begin{array}{c}\text { Not } \\
\text { stated }\end{array}$ & Total \\
\hline$\overline{\mathrm{PHN}}$ & 9 & $8^{*}$ & 3 & 1 & 3 & 24 \\
\hline $\begin{array}{l}\text { Postsurgical } \\
\text { treatment for } \\
\text { cancer }\end{array}$ & 9 & 6 & 8 & 2 & 1 & 26 \\
\hline Cancer etiology & 2 & 2 & 4 & 0 & 8 & $16^{\dagger}$ \\
\hline $\begin{array}{l}\text { Other/multiple } \\
\text { treatments for } \\
\text { cancer }\end{array}$ & 3 & 0 & 4 & 0 & 4 & 11 \\
\hline $\begin{array}{l}\text { Mixed: Cancer } \pm \\
\mathrm{PHN} \pm \text { treatment }\end{array}$ & 1 & 5 & 1 & 0 & 1 & 8 \\
\hline $\begin{array}{l}\text { Other unrelated } \\
\text { chronic pain }\end{array}$ & 0 & 2 & 3 & 0 & 4 & 9 \\
\hline $\begin{array}{l}\text { Pain etiology not } \\
\text { indicated }\end{array}$ & 0 & 0 & 1 & 0 & 0 & 1 \\
\hline All patients & 24 & 23 & 24 & 3 & 21 & $95^{\dagger}$ \\
\hline
\end{tabular}

*One patient unable to continue due to skin rash despite analgesic effect; ${ }^{\dagger}$ Two patients excluded because they never applied lidocaine 5\% patch. PHN Postherpetic neuralgia

are detailed in Table 2. The most common indications for L5\%P use were persistent postsurgical neuropathic pain (26 patients; $27 \%$ ), PHN (24 patients; $25 \%$ ) and neuropathic pain directly attributed to cancer (18 patients; 19\%). Postsurgical neuropathic pain occurred after thoracic surgery $(n=8)$, breast or associated axillary nodal surgery $(n=7)$, head and neck surgery $(n=4)$, other inguinal or axillary surgery $(n=3)$, limb amputation $(n=3)$ and tumour biopsy $(n=1)$. The presence of allodynia or cutaneous hypersensitivity was clearly documented in $60 \%$ of patients before patch application, whereas absence of allodynia was noted in another $13 \%$; no record was found for the remainder. Allodynia was most commonly observed and noted in patients with PHN, postsurgical neuropathic pain and mixed neuropathic pain syndromes (for example, PHN and underlying cancer). Allodynia was poorly documented in cases for which neuropathic pain was directly attributed to cancer.

The efficacy of L5\%P in the various neuropathic pain groups, as assessed by the audit reviewers, is summarized in Table 3. Two of 97 patients prescribed L5\%P, both with cancerrelated neuropathic pain, never actually applied the medication and were excluded from assessment of analgesic efficacy. Overall, L5\%P had a 'potent analgesic effect' in 24 of 95 patients (25\%) and a 'partial effect' in 23 patients (24\%). There was no analgesic effect or documentation of any benefit in 45 patients $(47 \%)$. L5\%P made pain worse, or application and removal of patches was intensely painful, in three patients (3.2\%). Patients with PHN and persistent postsurgical pain responded more frequently to application of L5\%P. A clearly beneficial, or 'potent', analgesic benefit of $\mathrm{L} 5 \% \mathrm{P}$ was apparent in patients treated for PHN (38\%), persistent postsurgical pain (35\%), pain due to other or multiple treatments for cancer (27\%), mixed neuropathic pain syndromes (13\%) and neuropathic pain directly attributed to cancer (12\%).

Documentation of allodynia was associated with improved documentation of the clinical effect of L5\%P (in 54 of 58 patients with allodynia), and apparent improved efficacy of 
TABLE 4

Duration of therapy with lidocaine 5\% patch (L5\%P)

\begin{tabular}{|c|c|c|c|c|c|c|}
\hline \multirow[b]{2}{*}{ Indication } & \multicolumn{6}{|c|}{$\begin{array}{l}\text { Patients with L5\%P prescribed for } \\
\text { stated duration, } n\end{array}$} \\
\hline & $\begin{array}{c}<1 \\
\text { week }\end{array}$ & $\begin{array}{c}<1 \\
\text { month }\end{array}$ & $\begin{array}{c}1-2 \\
\text { months }\end{array}$ & $\begin{array}{c}\text { 3-6 } \\
\text { months }\end{array}$ & $\begin{array}{c}7-12 \\
\text { months }\end{array}$ & $\begin{array}{c}>12 \\
\text { months }\end{array}$ \\
\hline $\mathrm{PHN}$ & 5 & 7 & 6 & 4 & 1 & 6 \\
\hline $\begin{array}{l}\text { Postsurgical treatment } \\
\text { for cancer }\end{array}$ & 6 & 11 & 7 & 3 & & 5 \\
\hline Cancer etiology & 5 & 11 & 5 & & 2 & \\
\hline $\begin{array}{l}\text { Other/multiple } \\
\text { treatments for cancer }\end{array}$ & 4 & 4 & 5 & 2 & & \\
\hline $\begin{array}{l}\text { Mixed: Cancer } \pm \text { PHN } \\
\pm \text { treatment }\end{array}$ & 1 & 3 & & 3 & & 2 \\
\hline $\begin{array}{l}\text { Other unrelated } \\
\text { chronic pain }\end{array}$ & 6 & 9 & & & & \\
\hline $\begin{array}{l}\text { Pain etiology not } \\
\text { indicated }\end{array}$ & & 1 & & & & \\
\hline All patients & 27 & 46 & 23 & 12 & 3 & 13 \\
\hline
\end{tabular}

topical lidocaine. Overall, the analgesic effect of L5\%P was rated as 'potent' in 38\% ( $n=22)$ and 'partial' in 24\% ( $n=14)$ of patients with neuropathic pain with allodynia; the same treatment was 'ineffective' in 26\% ( $\mathrm{n}=15)$ and either caused 'worse pain' or could not be continued in $5 \%(n=3)$. Of patients treated for PHN, 67\% had documented allodynia, and allodynia was present in all but one patient who subsequently derived a 'potent' benefit from L5\%P. Notably, all patients with postradiotherapy neuropathic pain who responded well to L5\%P (three of four patients) were noted to have allodynia. However, three patients with PHN and allodynia in proximity to an area of malignancy, radiation therapy or surgery derived minor or no benefit from L5\%P. Treatment with L5\%P was associated with total resolution of symptoms and cessation of all treatment in one patient with PHN and dysesthesias, but without allodynia.

The only adverse effect reported following application of L5\%P was new skin irritation or rash, described by eight patients and resulting in cessation of $\mathrm{L} 5 \% \mathrm{P}$ use in seven patients. One patient discontinued L5\%P use due to erythema but later tolerated patch application without adverse consequences. A fine, eczematous rash and generalized pruritis complicated long-term L5\% treatment for intercostobrachial neuralgic pain and allodynia of the upper arm and anterolateral chest wall following breast cancer surgery. The condition resolved after patch cessation but reccurred when the patient reapplied L5\%P, due to 'excellent' analgesia previously achieved. Subsequent dermatological testing revealed contact sensitivity to lidocaine without cross-sensitivity to other local anesthetics. There was no serious outcome reported in any patient.

Table 4 indicates the duration of therapy for the various classifications of neuropathic pain. The duration of therapy ranged from only a few days, to 66 months of intermittent use. Less than seven days' supply of $\mathrm{L} 5 \% \mathrm{P}$ was provided to $28 \%$ of patients with no further prescription; many of these patients indicated ceasing therapy after two to three days due to lack of perceived benefit. Overall, treatment was trialled for less than one month in 47\% of the audited patients, and continued for more than 12 months in a smaller proportion (13\%). Of note, some individuals described exacerbations of pain that could be managed by bursts of topical treatment; pain was otherwise manageable with standard antineuropathic medications. These patients used L5\%P intermittently, some over a prolonged period of several years, recommencing L5\%P treatment when pain flared, and describing a beneficial effect with patch reapplication.

Treatment was ongoing at the time of final audit in 13 patients. Reasons for cessation of L5\%P therapy were that treatment was ineffective or inadequate $(n=22)$, neuropathic pain resolved during treatment $(n=7)$, patient died of disease during therapy $(\mathrm{n}=7)$, patches caused rash or skin irritation $(n=7)$, patches would not adhere to the painful site $(n=3)$, patients disliked altered sensations, including paresthesia and numbness under the patch $(n=3)$, or that the patient relocated and could not access the patches $(n=1)$. A reason for stopping L5\%P therapy was not recorded in 32 patients; of these, treatment effect had been classed as potent in seven, partial in three, ineffective in five and not indicated in the remainder.

\section{DISCUSSION}

Neuropathic pain complicating cancer is often difficult to effectively manage, and multimodal therapy is limited by poor tolerance, incomplete compliance and risk of drug interactions (2). The presence of neuropathic pain significantly increases the median time to achieve stable pain control and the number of adjuvant medications required in patients referred to a palliative care service (2). The concept of a topical, local anesthetic patch as therapy for allodynia has great appeal to clinicians and patients due to the simplicity of a topical formulation, the benefit of the patch formulation as a barrier protecting hypersensitive skin from external stimuli, and the lack of clinically significant systemic absorption, drug interactions and other serious adverse effects. Pharmacokinetic studies indicate that systemic absorption of lidocaine is minimal following application of three patches $(3 \% \pm 2 \%$ of a total dose of $2100 \mathrm{mg})$, with the mean maximum plasma lidocaine concentration (mean $T_{\max }$ ) reaching $0.13 \mathrm{mg} / \mathrm{L}$ after $11 \mathrm{~h}$, and no accumulation after repeated dosing using a $12 \mathrm{~h}$ on-off cycle $(8,9)$. Plasma concentrations were well below the antiarrhythmic threshold of lidocaine $(0.6 \mathrm{mg} / \mathrm{L})$, the minimum plasma concentration recommended for therapeutic antiarrythmic efficacy $(1.5 \mathrm{mg} / \mathrm{L})$ and significant toxicity limits $(5 \mathrm{mg} / \mathrm{L})$. Additional studies suggest low systemic absorption with $18 \mathrm{~h} /$ day and $24 \mathrm{~h} /$ day dosing (10).

There is very little published information regarding the specific role of $\mathrm{L} 5 \% \mathrm{P}$ for neuropathic pain in individuals with cancer. In the Australian setting, the L5\%P formulation used is not registered and prescribing fell under the regulations of a national Special Access Scheme. Despite these restrictions and the expense of importation, the intractable nature of neuropathic pain in patients within our cancer centre, together with the potential benefits and lack of systemic adverse effects of L5\%P, led to keen uptake of the topical formulation for management of several groups of patients with features of neuropathic pain referred to the Pain and Palliative Care Service. The present review of $\mathrm{L} 5 \% \mathrm{P}$ prescribing for neuropathic pain within a cancer centre is flawed by the limitations of the retrospective audit process and a lack of standardized tools for assessment of neuropathic pain and outcomes of therapy in all patients. However, the audit provides useful information regarding the 
spectrum of patients for whom this therapy was selected, and may guide careful patient selection and outcome measures for future controlled trials of a potentially therapeutic agent.

A major obstacle to developing treatment guidelines for neuropathic pain in cancer is the recruitment of patients with advanced malignancy to controlled clinical trials relating to symptom control (11). Often, rigorous inclusion criteria further restrict enrollment to supportive care clinical trials. In a multicentre, randomized controlled trial of L5\%P for chronic postsurgical neuropathic pain in patients with cancer, early closure was related to poor subject accrual (12). Similarly, a few controlled studies and limited evidence from small trials guide the use of other topical agents (13), intravenous local anesthetics $(14,15)$, antidepressants (16-18), anticonvulsants $(19,20)$, combined anticonvulsant-opioid therapy $(21,22)$ and radiotherapy (23) for neuropathic pain in cancer. The lack of definition of the mechanisms of cancer-associated neuropathic pain in therapeutic trials often weakens the usefulness of the data obtained in specific neuropathic pain syndromes.

Wide-ranging applications for L5\% $\mathrm{P}$ in controlled trials, small studies and case reports would suggest potential uses for treating neuropathic pain in the cancer setting. In the general population, lidocaine patches have been demonstrated to be safe and effective treatment for PHN in randomized controlled trials $(6,7)$. L5\%P was registered for the treatment of pain due to PHN by the United States Food and Drug Administration in 1999 (Lidoderm 5\%) and by the Medicines and Healthcare products Regulatory Agency in the United Kingdom in 2007 (Versatis 5\% medicated plaster; Grünenthal Group, Germany). Randomized controlled trials suggest a similar role for L5\%P in the management of other focal peripheral neuropathic pain syndromes when allodynia is present (24), for nonallodynic neuropathic pain (25) and carpal tunnel syndrome (26). A lidocaine patch safety and systemic absorption profile has been established for patch application only over intact skin. Notably, a recent randomized controlled trial in patients with acute herpes zoster, in which patches were applied to intact sensitive skin without vesicles every $12 \mathrm{~h}$ for $48 \mathrm{~h}$, also demonstrated a significant analgesic benefit relative to vehicle patches (27). Other case reports and open-label trials suggest potential applications in adolescents with neuropathic pain (28), other varied pain states (29-35), and when used as combination therapy with gabapentin (36). Despite consensus guidelines suggesting the use of L5\%P as first-line therapy for PHN and other peripheral focal neuropathic pain states (5), a systematic review in 2007 concluded that there was, at that time, insufficient evidence from controlled clinical trials to support such a recommendation (37).

A number of neuropathological changes underpin the pain of $\mathrm{PHN}$, and patients often present with features of both central and peripheral neuropathic pain, including stimulus-evoked tactile allodynia, steady throbbing or burning pain, and spontaneous lancinating pain that may fluctuate with specific unique characteristics (38-40). Patients with PHN were well represented in the present audit. Many cancer patients with concomitant PHN derived considerable benefit after L5\%P application, with treatment extending beyond three months in 50\% of patients. The specific features of neuropathic pain that improved were not consistently documented; however, allodynia was a consistent feature in almost all PHN patients who subsequently derived a 'potent' benefit from L5\%P. Early randomized controlled trials of L5\%P for PHN highlighted that allodynia was often problematic, indicative of nerve dysfunction and particularly responsive to application of topical lidocaine $(6,7)$. In $\mathrm{PHN}$, distinct afferent fibre types and central processes appear to mediate allodynia and spontaneous pain. The mechanisms by which L5\%P decreases PHN pain may include action on cutaneous afferent nerve sodium channels, because low concentrations of lidocaine can restore normal firing patterns in nerves rendered hyperexcitable by delayed sodium channel inactivation (41). Reduction of afferent ectopic activity may reduce central sensitization. L5\%P causes greater pain reduction when PHN is associated with loss of function of cutaneous $\mathrm{C}$ nociceptors within the allodynic skin (42). Efficacy may relate to both the pharmacological and physical barrier effects of the patch.

Surgical procedures for cancer, notably thoracotomy, limb amputation, breast surgery and dissections of axillary, inguinal or cervical lymph nodes, may also result in chronic neuropathic pain syndromes (43). Persistent allodynia, paroxysmal and burning pain or dysesthesia are common and distressing following surgery for cancer, and patients often misinterpret pain or discomfort as signifying the presence of tumour. During the audit period, persistent postoperative pain was the most frequent indication for L5\% Prescription. Allodynia was present in $80 \%$ of this group and appeared to be a clinical stimulus for a trial of L5\%P. Neuropathic pain, including allodynia, resolved completely in three individuals with persistent postsurgical pain during treatment with $\mathrm{L} 5 \% \mathrm{P}$, enabling gradual reduction in the frequency of patch application, resulting in cessation of therapy.

Although our experience suggests a useful role for L5\%P, a multicentre, randomized controlled trial comparing L5\%P and vehicle patches for persistent postsurgical pain in patients with cancer could find no benefit in terms of a reduction in pain intensity rating (12). This crossover study, in which subjects used each treatment for a four-week period, closed early due to low recruitment, possibly related to extensive inclusion criteria. Only 18 subjects completed both treatment arms, rendering the study inadequately powered to detect small but real differences between L5\%P and vehicle patches. However, Brief Pain Inventory interference scores improved with L5\%P, including significant improvements in the domains of general activity $(\mathrm{P}=0.02)$, work $(\mathrm{P}=0.04)$ and relations with others $(\mathrm{P}=0.02)$. Adverse events were no different with the active and vehicle patches. The authors questioned whether four weeks of treatment constituted an adequate trial. Of note, subjects were excluded from this controlled trial if they had received concurrent radiation therapy to the painful area. The contribution of radiation therapy to the generation of neuropathic pain syndromes is unclear and remains another important area for further investigation.

There are very limited data regarding the use of topical lidocaine for neuropathic pain resulting from tissue destruction, compression or expansion by cancer. The impact of L5\% on pain in the present audit group was the most difficult to define, possibly due to the complexity of symptoms, mixed features of neuropathic and nociceptive pain, unstable pain, advanced malignancy and multiple concomitant therapies. Only two patients, both with allodynia in the region of pain, responded well to $\mathrm{L} 5 \% \mathrm{P}$ - one described pain and allodynia in the foot due to neural compression by a pelvic sarcoma, and the 
other obtained considerable relief of allodynia and spontaneous pain when $\mathrm{L} 5 \% \mathrm{P}$ was applied over subcutaneous recurrent breast carcinoma deposits. Other published case reports suggest a potential application for $\mathrm{L} 5 \% \mathrm{P}$ after spinal cord injury for the management of 'at-level' neuropathic pain experienced in dermatomes close to the level of injury, believed to be related to localized nerve root compression, spinal trauma with central hyperexcitability, or both. A patient with spinal cord compression due to pancreatic cancer and at-level neuropathic pain with allodynia after decompression surgery responded with complete pain relief within hours after L5\%P (44). Rapid analgesia was also achieved within hours of L5\% $\mathrm{P}$ application over areas of pain and allodynia in the thighs of a patient with a vertebral fracture (nonmalignant), T12 incomplete spinal cord lesion and bilateral at-level neuropathic pain (45). In this latter case study, careful assessment, including Quantitative Sensory Testing and the effects of both topical capsaicin and lidocaine, provided evidence for a role of peripheral afferent nerves contributing to neuropathic pain. The authors hypothesized that allodynia in this patient was likely due to the projection of A-beta afferents onto hyperexcitable dorsal horn neurons in the spinal cord, and that the action of topical lidocaine may have blocked spontaneous activity in these afferents contributing to central sensitization.

What constitutes a reasonable duration of treatment with topical lidocaine remains unclear. The clinical impression in the present audit was that a beneficial response to patch application was apparent within hours or, at most, a few days after patch application. Patients often indicated periods of rapid pain relief followed by recurrence of pain correlating with the $12 \mathrm{~h}$ on-off cycle of L5\%P treatment. After deliberation of the audit data and the costs of ongoing treatment, our service determined that a 10 - to 14 -day trial of $\mathrm{L} 5 \% \mathrm{P}$ was optimal before determining whether to continue therapy. Patients who indicated a clear or possible benefit from L5\%P would be provided with ongoing treatment, and subsequently encouraged to trial intermittent periods of therapy when tolerated. This regime is not consistent with with the view expressed by Cheville et al (12) that a four-week period may be inadequate to assess efficacy but consistent with early controlled trials in which benefits were seen within 14 days, and many case reports describing relief within hours of patch application. Brain imaging studies suggest that different aspects of the pain experience may respond to L5\%P therapy at different rates - sensory and affective brain regions responded to short-term treatment $(6 \mathrm{~h})$ with L5\%P, whereas activity in reward-related areas decreased with longer-term treatment (two weeks) (46). Another clinical issue is the apparent efficacy, in some trial subjects, of vehicle patches. This may not simply be a placebo response because the physical barrier effect of patches, either vehicle or L $5 \%$, may provide some therapeutic benefit.

In the present audit series, the incidence of mild skin reactions at the application site was approximately $8 \%$. Shortterm vehicle-controlled studies report similar low rates of adverse events (skin reaction) in placebo and active treatment groups $(7,27)$. The lidocaine patch formulations contain both propylene glycol and parabens, which may induce skin irritation or contact dermatitis. Contact allergy to aminoacylamide local anesthetics (lidocaine, mepivacaine, prilocaine and bupivacaine) is rare, with the reported prevalence of lidocaine contact allergy in the United States being approximately $0.7 \%$ (47). Topical treatments for pruritus ani have been reported to be the most common cause of sensitization to lidocaine (48). Widespread use of lidocaine by multiple routes and potential cross-sensitization between local anesthetics raises the dilemma of whether to further investigate sensitivity reactions with skin testing. For patients in whom lidocaine contact sensitivity is suspected, current guidelines may be consulted and referral for patch testing considered (49). Such testing revealed true contact sensitivity to lidocaine in one audit patient.

In regions where $\mathrm{L} 5 \% \mathrm{P}$ is unavailable, lidocaine $5 \%$ gel under occlusive dressing (eg, Tegaderm; 3M, USA) or plastic wrap may provide some benefit. In a small, double-blinded trial for PHN, lidocaine gel provided 'slight' to 'moderate' pain relief, significantly better than placebo, and reduction of allodynia (50). Generally, systemic absorption was modest, but a trend of greater lidocaine absorption with gel than with patch application has been observed (9); caution is required if gel is applied to large areas or areas of increased vascularity.

\section{CONCLUSION}

Despite the limitations of retrospective review, the present audit identified patients with neuropathic pain within a cancer setting who were selected for treatment and successfully managed with topical lidocaine patches. The topical therapy appealed to both clinicians and patients due to lack of significant adverse effects. Approximately one-quarter of patients for whom lidocaine patches were prescribed appeared to derive clear benefit. A greater proportion of patients with cancer and PHN, or persistent postsurgical neuropathic pain, seemed to derive benefit and continued treatment. Allodynia was a significant feature of neuropathic pain in at least $60 \%$ of patients, and appeared to be indicative of improved responsiveness to L5\%P. However, the present audit does not purport to be a clinical trial; lack of firm inclusion criteria for treatment, standardized assessment tools and consistent clinical review prevented the investigators from determining precisely which cancer pain groups gained significant benefit from L5\%P. The audit raised questions regarding patient selection, careful assessment of the neuropathic pain mechanisms and features, the optimal duration of a trial of therapy, the frequency of review and evaluation of ongoing benefit, and follow-up of skin reactions.

Based on the higher incidence of documented efficacy in patients with demonstrated allodynia and in patients with neuropathic pain syndromes commonly associated with allodynia, such as PHN and postsurgical neuropathic pain, we recommend that cancer patients presenting with neuropathic pain and demonstrable allodynia should be considered for a trial of treatment with L5\%P for a minimum period of two weeks before reassessment. Before institution of therapy, and at each review, pain characteristics should be assessed using a validated tool such as the Neuropathic Pain Scale $(51,52)$ in addition to assessment of sleep disturbance by pain and functional ability; other analgesic medication doses should be stabilized during the trial. L5\%P therapy should cease after two to four weeks if no reduction in neuropathic pain or improvement in sleep and functional status is demonstrated. 
If pain becomes problematic during the $12 \mathrm{~h}$ off-period, consideration should be given to longer application periods, although a daily patch-free period is recommended to ensure that any cutaneous erythema settles. Patients require clear instructions regarding the optimal site and duration of $\mathrm{L} 5 \% \mathrm{P}$ application. Ideally, individualized $\mathrm{N}$-of-1 repeated trials, including crossover trials with two-week treatment phases and use of clear protective dressing or wrap as a comparator, should be performed to identify whether perceived benefits from L5\%P relate to topical lidocaine or to protection of allodynic skin from external stimuli. In addition, larger randomized controlled trials of patients with neuropathic pain after surgery, or combined surgery and radiotherapy, are required because previous studies have been inconclusive due to stringent inclusion criteria and poor recruitment. Optimal recruitment will likely be in centres where oncology treatment teams actively support specialist pain services and research relating to quality of life issues, and promptly refer cancer patients with suspected neuropathic pain for assessment and potential study enrollment.

ACKNOWLEDGEMENTS: The assistance of the Peter MacCallum Cancer Centre Pharmacy Department, notably Ms Sandy Scholes and Ms Michelle Cassumbhoy, with provision of prescription listings for this audit is greatly appreciated.

\section{REFERENCES}

1. Caraceni A, Portenoy RK. An international survey of cancer pain characteristics and syndromes. Pain 1999;82:263-74.

2. Fainsinger RL, Nekolaichuk CL, Lawlor PG, Neumann CM, Hanson J, Vigano A. A multicenter study of the revised Edmonton Staging System for classifying cancer pain in advanced cancer patients. J Pain Symptom Manage 2005;29:224-37.

3. Scottish Intercollegiate Guidelines Network. SIGN 106: Control of pain in adults with cancer. $<$ http://www.sign.ac.uk/> (Version current at November 5, 2008).

4. National Comprehensive Cancer Network, Inc. NCCN Clinical Practice Guidelines in Oncology - V.1.2009: Adult Cancer Pain. $<$ http://www.nccn.org/> (Version current at March 16, 2009).

5. Dworkin RH, O'Connor AB, Backonja M, et al. Pharmacologic management of neuropathic pain: Evidence-based recommendations. Pain 2007;132:237-51.

6. Rowbotham MC, Davies PS, Verkempinck C, Galer BS. Lidocaine patch: Double-blind controlled study of a new treatment method for post-herpetic neuralgia. Pain 1996;65;39-44.

7. Galer BS, Rowbotham MC, Perander J, Friedman E. Topical lidocaine patch relieves postherpetic neuralgia more effectively than a vehicle topical patch: Results of an enriched enrollment study. Pain 1999;80:533-8.

8. Comer AM, Lamb HM. Lidocaine patch 5\%. Drugs 2000;59:245-9.

9. Campbell BJ, Rowbotham M, Davies PS, Jacob P III, Benowitz NL. Systemic absorption of topical lidocaine in normal volunteers, patients with post-herpetic neuralgia, and patients with acute herpes zoster. J Pharm Sci 2002;91:1343-50.

10. Gammaitoni AR, Alvarez NA, Galer BS. Safety and tolerability of the lidocaine patch $5 \%$, a targeted peripheral analgesic: A review of the literature. J Clin Pharmacol 2003;43:111-7.

11. Sinnott C. Problems recruiting cancer patients to a comparative clinical trial of drug treatments for neuropathic pain in palliative care. J Pain Symptom Manage 2002;23:270-2.

12. Cheville AL, Sloan JA, Northfelt DW, et al. Use of a lidocaine patch in the management of postsurgical neuropathic pain in patients with cancer: A phase III double-blind crossover study (N01CB). Support Care Cancer 2009;17:451-60.

13. Ellison N, Loprinzi CL, Kugler J, et al. Phase III placebo-controlled trial of capsaicin cream in the management of surgical neuropathic pain in cancer patients. J Clin Oncol 1997;15:2974-80.

14. Bruera E, Ripamonti C, Brenneis C, Macmillan K, Hanson J. A randomized double-blind crossover trial of intravenous lidocaine in the treatment of neuropathic cancer pain. J Pain Symptom Manage 1992;7:138-40.

15. Ellemann K, Sjogren P, Banning AM, Jensen TS, Smith T, Geertsen P. Trial of intravenous lidocaine on painful neuropathy in cancer patients. Clin J Pain 1989;5:291-4.

16. Kalso E, Tasmuth T, Neuvonen PJ. Amitriptyline effectively relieves neuropathic pain following treatment of breast cancer. Pain 1996;64:293-302.

17. Tasmuth T, Hartel B, Kalso E. Venlafaxine in neuropathic pain following treatment of breast cancer. Eur J Pain 2002;6:17-24.

18. Mercadante S, Arcuri E, Tirelli W, Villari P, Casuccio A. Amitriptyline in neuropathic cancer pain in patients on morphine

therapy: A randomized placebo-controlled, double-blind crossover study. Tumori 2002;88:239-42.

19. Caraceni A, Zecca E, Bonezzi C, et al. Gabapentin for neuropathic cancer pain: A randomized controlled trial from the Gabapentin Cancer Pain Study Group. J Clin Oncol 2004;22:2909-17.

20. Wiffen PJ, Rees J. Lamotrigine for acute and chronic pain. Cochrane Database Syst Rev 2007:CD006044.

21. Keskinbora K, Pekel AF, Aydinli I. Gabapentin and an opioid combination versus opioid alone for the management of neuropathic cancer pain: A randomized open trial. J Pain Symptom Manage 2007;34:183-9.

22. Arbaiza D, Vidal O. Tramadol in the treatment of neuropathic cancer pain: A double-blind, placebo-controlled study. Clin Drug Investig 2007;27:75-83.

23. Roos DE, Turner SL, O'Brien PC, et al. Randomized trial of 8 Gy in 1 versus $20 \mathrm{~Gy}$ in 5 fractions of radiotherapy for neuropathic pain due to bone metastases (Trans-Tasman Radiation Oncology Group, TROG 96.05). Radiother Oncol 2005;75:54-63.

24. Meier T, Wasner G, Faust M, et al. Efficacy of lidocaine patch $5 \%$ in the treatment of focal peripheral neuropathic pain syndromes: A randomized, double-blind, placebo-controlled study. Pain 2003;106:151-8.

25. Galer BS. Effectiveness and safety of lidocaine patch 5\%. J Fam Pract 2002;51:867-8.

26. Nalamachu S, Crockett RS, Mathur D. Lidocaine patch 5 for carpal tunnel syndrome: How it compares with injections: A pilot study. J Fam Pract 2006;55:209-14.

27. Lin PL, Fan SZ, Huang CH, et al. Analgesic effect of lidocaine patch $5 \%$ in the treatment of acute herpes zoster: A double-blind and vehicle-controlled study. Reg Anesth Pain Med 2008;33:320-5.

28. Nayak S, Cunliffe M. Lidocaine 5\% patch for localized chronic neuropathic pain in adolescents: Report of five cases. Paediatr Anaesth 2008;18:554-8.

29. Desai MJ, Siriki R, Wang D. Treatment of pain in Dercum's disease with Lidoderm (lidocaine 5\% patch): A case report. Pain Med 2008;9:1224-6.

30. Karmarkar A, Lieberman I. Management of complex regional pain syndrome type II using lidoderm $5 \%$ patches. Br J Anaesth 2007;98:261-2.

31. Herrmann DN, Barbano RL, Hart-Gouleau S, Pennella-Vaughan J, Dworkin RH. An open-label study of the lidocaine patch $5 \%$ in painful idiopathic sensory polyneuropathy. Pain Med 2005;6:379-84.

32. Gimbel J, Linn R, Hale M, Nicholson B. Lidocaine patch treatment in patients with low back pain: Results of an open-label, nonrandomized pilot study. Am J Ther 2005;12:311-9.

33. Davis MD, Sandroni P. Lidocaine patch for pain of erythromelalgia: Follow-up of 34 patients. Arch Dermatol 2005;141:1320-1.

34. Galer BS, Gammaitoni AR, Oleka N, Jensen MP, Argoff CE. Use of the lidocaine patch $5 \%$ in reducing intensity of various pain qualities reported by patients with low-back pain. Curr Med Res Opin 2004;20(Suppl 2):S5-12.

35. Barbano RL, Herrmann DN, Hart-Gouleau S, Pennella-Vaughan J, Lodewick PA, Dworkin RH. Effectiveness, tolerability, and impact on quality of life of the $5 \%$ lidocaine patch in diabetic polyneuropathy. Arch Neurol 2004;61:914-8. 
36. White WT, Patel N, Drass M, Nalamachu S. Lidocaine patch 5\% with systemic analgesics such as gabapentin: A rational polypharmacy approach for the treatment of chronic pain. Pain Med 2003;4:321-30.

37. Khaliq W, Alam S, Puri N. Topical lidocaine for the treatment of postherpetic neuralgia. Cochrane Database Syst Rev 2007:CD004846.

38. Dworkin RH, Portenoy RK. Pain and its persistence in herpes zoster. Pain 1996;67:241-51.

39. Dworkin RH, Gnann JW Jr, Oaklander AL, Raja SN, Schmader KE, Whitley RJ. Diagnosis and assessment of pain associated with herpes zoster and postherpetic neuralgia. J Pain 2008;9(1 Suppl 1):S37-44.

40. Foss JM, Apkarian AV, Chialvo DR. Dynamics of pain: Fractal dimension of temporal variability of spontaneous pain differentiates between pain states. J Neurophysiol 2006;95:730-6.

41. Persaud N, Strichartz GR. Micromolar lidocaine selectively blocks propagating ectopic impulses at a distance from their site of origin. Pain 2002;99:333-40.

42. Wasner G, Kleinert A, Binder A, Schattschneider J, Baron R. Postherpetic neuralgia: Topical lidocaine is effective in nociceptordeprived skin. J Neurol 2005;252:677-86.

43. Kehlet H, Jensen TS, Woolf CJ. Persistent postsurgical pain: Risk factors and prevention. Lancet 2006;367:1618-25.

44. Hans GH, Robert DN, Van Maldeghem KN. Treatment of an acute severe central neuropathic pain syndrome by topical application of lidocaine 5\% patch: A case report. Spinal Cord 2008;46:311-3.

45. Wasner G, Naleschinski D, Baron R. A role for peripheral afferents in the pathophysiology and treatment of at-level neuropathic pain in spinal cord injury? A case report. Pain 2007;131:219-25.

46. Geha PY, Baliki MN, Chialvo DR, Harden RN, Paice JA, Apkarian AV. Brain activity for spontaneous pain of postherpetic neuralgia and its modulation by lidocaine patch therapy. Pain 2007;128:88-100.

47. Mackley CL, Marks JG Jr, Anderson BE. Delayed-type hypersensitivity to lidocaine. Arch Dermatol 2003;139:343-6.

48. Handfield-Jones SE, Cronin E. Contact sensitivity to lignocaine. Clin Exp Dermatol 1993;18:342-3.

49. Thyssen JP, Menne T, Elberling J, Plaschke P, Johansen JD. Hypersensitivity to local anaesthetics - update and proposal of evaluation algorithm. Contact Dermatitis 2008;59:69-78

50. Rowbotham MC, Davies PS, Fields HL. Topical lidocaine gel relieves postherpetic neuralgia. Ann Neurol 1995;37:246-53.

51. Galer BS, Jensen MP. Development and preliminary validation of a pain measure specific to neuropathic pain: The Neuropathic Pain Scale. Neurology 1997;48:332-8.

52. Jensen MP, Dworkin RH, Gammaitoni AR, Olaleye DO, Oleka N, Galer BS. Assessment of pain quality in chronic neuropathic and nociceptive pain clinical trials with the Neuropathic Pain Scale. J Pain 2005;6:98-106. 


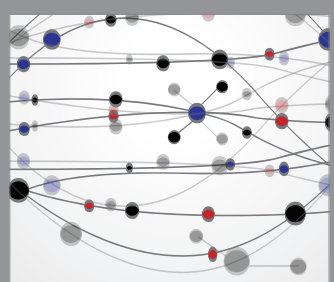

The Scientific World Journal
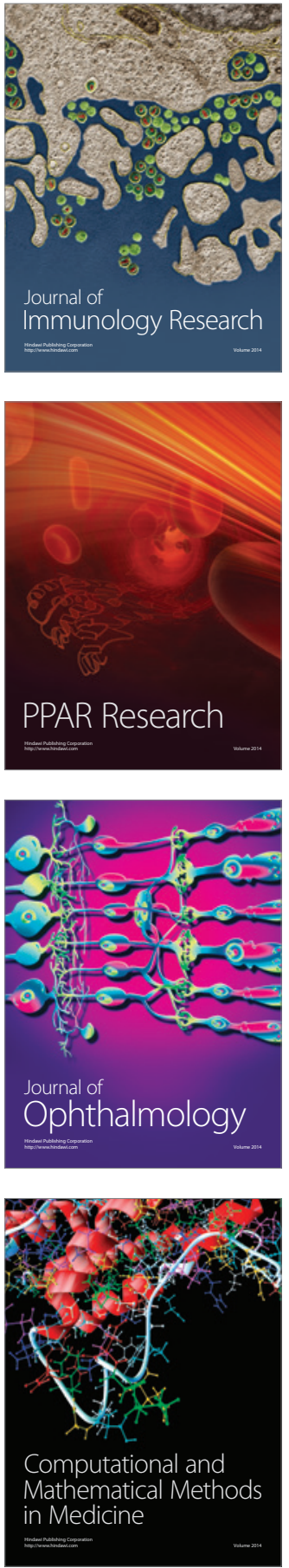

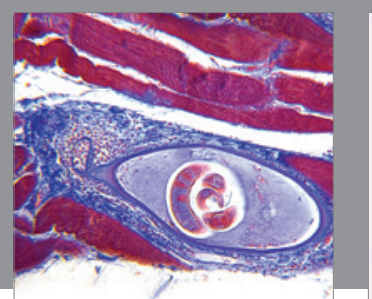

Gastroenterology Research and Practice

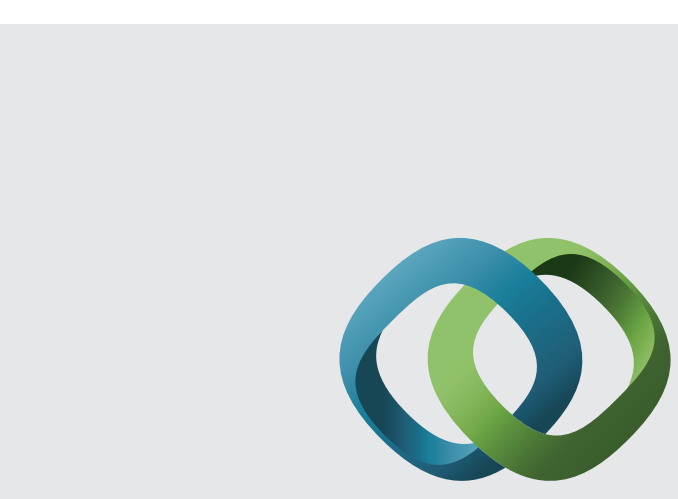

\section{Hindawi}

Submit your manuscripts at

http://www.hindawi.com
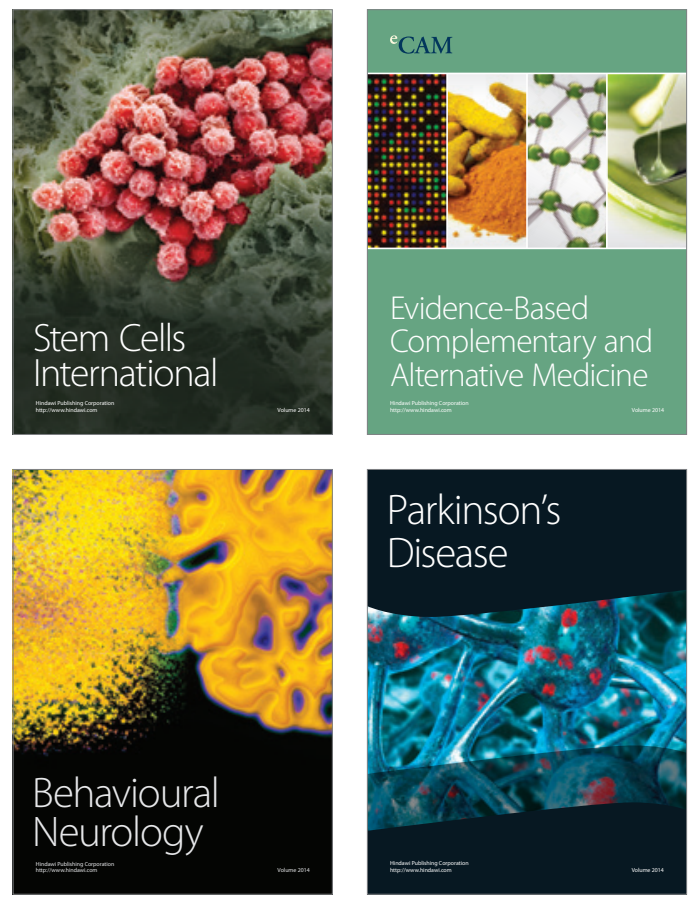
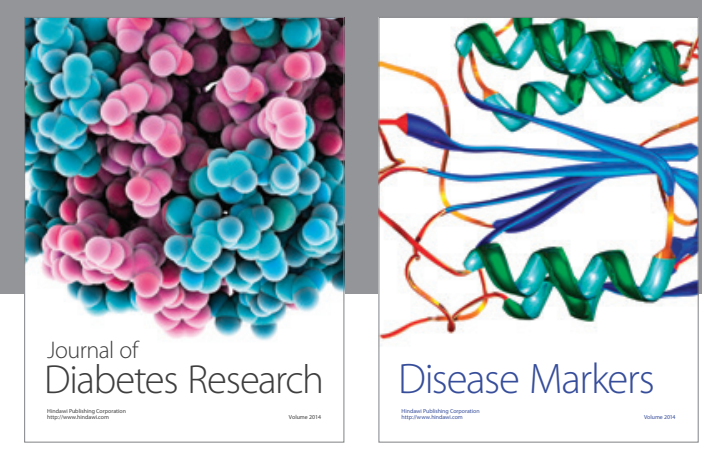

Disease Markers
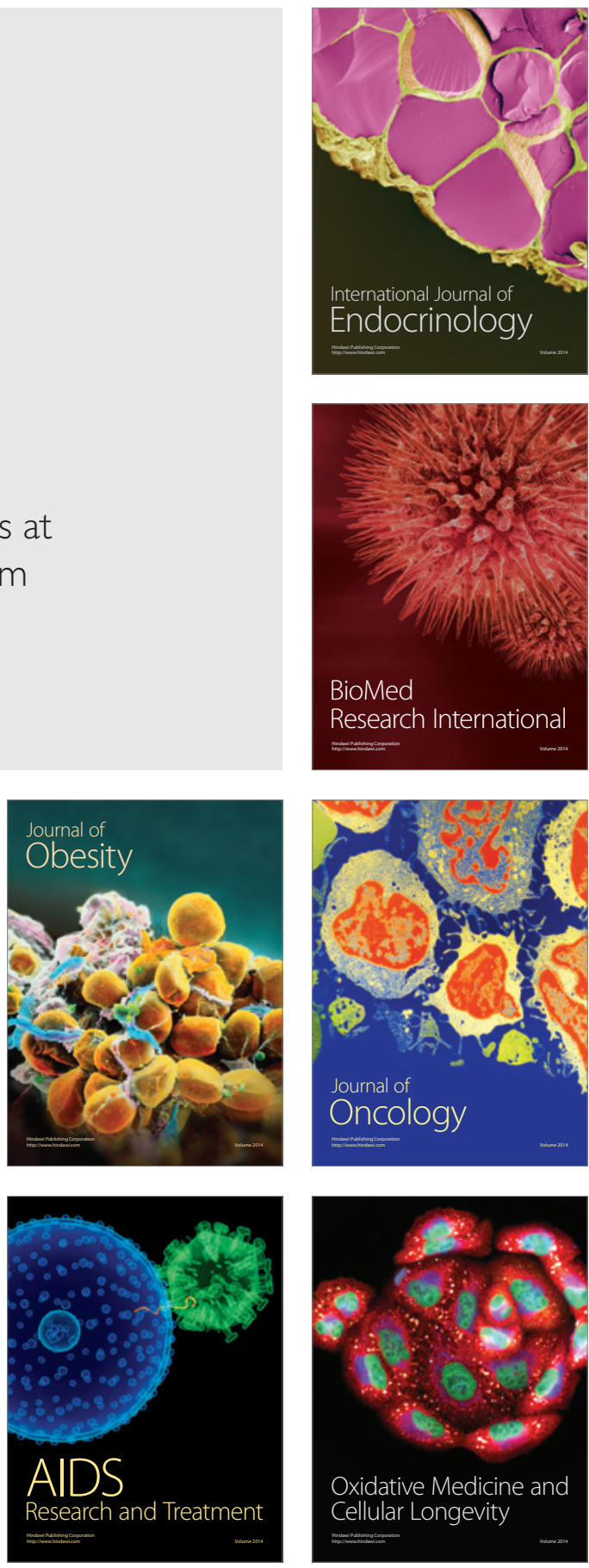